\begin{tabular}{|c|c|}
\hline Title & Nonlinear Iron Electrochemical Oscillator : Coupling and Photo Effects \\
\hline Author(s) & Nakabay ashi, S.; Zama, K.; U osaki, K. \\
\hline Citation & $\begin{array}{l}\text { Journal of The Electrochemical Society, 143(7), 2258-2262 } \\
\text { https://doi.org/10.1149/1.1836990 }\end{array}$ \\
\hline Issue Date & 1996 \\
\hline Doc URL & http:/hdl.handle.net/2115/50250 \\
\hline Rights & $\begin{array}{l}\text { () The Electrochemical Society, Inc. 1996. All rights reserved. Except as provided under U.S. copyright law, this work } \\
\text { may not be reproduced, resold, distributed, or modified without the express permission of The Electrochemical Society } \\
\text { (ECS). The archival version of this work was published in J. Electrochem. Soc. } 1996 \text { volume 143, issue 7, 2258-2262. }\end{array}$ \\
\hline Type & article \\
\hline File Information & JES143-7_2258-2262.pdf \\
\hline
\end{tabular}

Instructions for use 


\section{Nonlinear Iron Electrochemical Oscillator: Coupling and Photo Effects}

S. Nakabayashi, K. Zama and K. Uosaki

J. Electrochem. Soc. 1996, Volume 143, Issue 7, Pages 2258-2262.

doi: 10.1149/1.1836990

Email alerting Receive free email alerts when new articles cite this article - sign up service in the box at the top right corner of the article or click here

To subscribe to Journal of The Electrochemical Society go to: http://jes.ecsdl.org/subscriptions

(C) 1996 ECS - The Electrochemical Society 
$v_{\text {avg }} \quad$ average fluid speed, $\mathrm{cm} / \mathrm{s}$

$V$ electrode potential, $\mathrm{V}$

$V_{\mathrm{e}} \quad$ equilibrium electrode potential (corresponding to $i=0$ ), $\mathrm{V}$

$X, Y, Z$ rectangular coordinates, $\mathrm{cm}$

$x, y, z$ rectangular coordinates scaled to the disk radius $a$

$\alpha \quad(4 / \pi) i_{0, \infty} / i_{\mathrm{D}}$

transfer coefficient

oblate spheroidal coordinate

dimensionless coordinate, $1-e^{-\tilde{\Gamma}}$

angular variable about the $z$-axis

oblate spheroidal coordinate

$\tan (\bar{\theta})=\alpha W^{-\beta}=a k_{\mathrm{c}}^{\prime} / D$

\section{REFERENCES}

1. M. W. Verbrugge and D. R. Baker, This Journal, 143, 197 (1996).

2. J. Newman, in Electroanalytical Chemistry, Vol. 6 Chap. 3, A. J. Bard, Editor, Marcel Dekker, Inc., New York (1973).

3. C. G. Phillips, Q. J. Mech. Appl. Math., 43, 135 (1990)

4. H. A. Stone, Phys. Fluids A, 1, 1112 (1989).

5. D. K. Lambert, M. W. Verbrugge, and B. J. Koch, U.S. Pat. 5,361,624 (1994).

6. R. B. Bird, W. E. Stewart, and E. N. Lightfoot, Transport Phenomena, Wiley, New York, (1960).

7. H. Schlichting, Boundary-Layer Theory, 7 th ed., translated by J. Kestin, McGraw-Hill, New York (1979).

8. K. J. Vetter, Elektrochemische Kinetik, SpringerVerlag, Berlin (1961). [English edition: Electrochemical Kinetics, S. Bruckenstein and B.
Howard, translation editors, Academic Press, New York (1967).]

9. P. L. T. Brian, AIChE J., 7, 367 (1961).

10. A. J. Bard and L. R. Faulkner, Electrochemical Methods, Wiley, New York (1980)

11. J. Newman, Electrochemical Systems, 2nd ed., Prentice-Hall, Englewood Cliffs, NJ (1991).

12. H. S. Carslaw and J. C. Jaeger, Conduction of Heat in Solids, 2nd ed., p. 215, Oxford Press, London, England (1959).

13. Y. Saito, Rev. Polarog., 15, 177 (1968) (Japan).

14. D. R. Baker and M. W. Verbrugge, This Journal, 137, $3836(1990)$

15. M. W. Verbrugge, D. R. Baker, and J. Newman, Electrochim. Acta, 38, 1649 (1993).

16. P. Moon and D. E. Spencer, Field Theory Handbook, 2nd ed., Springer Verlag, Berlin (1971).

17. Handbook of Mathematical Functions with Formulas, Graphs, and Mathematical Tables, M. Abramowitz and I. A. Stegun, Editors, pp. 751-769, National Bureau of Standards, Applied Mathematics Series 55 (1964).

18. M. W. Verbrugge and D. R. Baker, J. Phys. Chem., 96, 4572 (1992)

19. M. W. Verbrugge, AIChE J., 41, 1550 (1995).

20. J. P. Hoare, The Electrochemistry of Oxygen, Interscience Publishers, New York (1968)

21. V. G. Levich, Physicochemical Hydrodynamics, Prentice-Hall, Englewood Cliffs, NJ (1962).

22. J. Newman, This Journal, 113, 501 (1966).

\title{
Nonlinear Iron Electrochemical Oscillator: Coupling and Photo Effects
}

\author{
S. Nakabayashi, ${ }^{a, b}$ K. Zama, ${ }^{b}$ and K. Uosaki*,b \\ ${ }^{a}$ PRESTO, Research Development Corporation of Japan, and ${ }^{b}$ Physical Chemistry Laboratory, Department of \\ Chemistry, Faculty of Science, Hokkaido University, Sapporo 060, Japan
}

\section{ABSTRACT}

The constant potential oxidation of iron in aqueous sulfuric acid solution induces a self-sustained nonlinear oscillation of the current. Here, two independently controlled iron electrodes become synchronized to each other as the distance between the electrodes is reduced. The temporal pattern of the synchronization is a function of the potential difference between the electrodes. The oscillation frequency of the iron electrode can be changed by irradiation with visible light.

The temporal and spatial patterns formed by chemical systems have been studied extensively. ${ }^{1}$ The nonlinearity in some chemical steps induces an instability in the overall reaction. ${ }^{2}$ There has been a lot of discussion about the time evolution of nonlinear chemical reactions with regard to chemically induced chaos. ${ }^{3-5}$ Much effort has been put into studying the interference of self-sustained chemical systems: the study of nonlinear chemical systems exposed to some periodic external input, i.e., forced systems, ${ }^{6,7}$ and/or of two more reactors being coupled together in some way. ${ }^{8-10}$

Heterogeneous nonlinear chemical reactions also have been studied in the field of surface science ${ }^{11-13}$ and electrochemistry. ${ }^{14-17}$ This is especially true for electrochemical systems which consist of electrode surface processes which depend upon mass transfer to and from the electrolyte solution. A lot of exotic bistable phenomena can be induced by mass transport. There have been considerable experimental and theoretical studies of electrochemical reactions which undergo sustained, temporal oscillations under constant current or constant potential conditions. ${ }^{1}$ One of the most widely studied systems is the electrodissolution of iron in aqueous sulfuric acid..$^{18-20}$ The oscillato-

* Electrochemical Society Active Member. ry behavior of this system is relatively simple to control and continues for long periods. The origin of bistability in iron electrodistribution is electrode repassivation by the surface oxide. The stability of the surface oxide is governed by electrode potential and $\mathrm{pH}$ at the electrode interface. The bistable oscillatory behavior of the iron electrode is induced by coupling between the surface process of oxide passivation and the mass transfer of protons in the electrolyte solution, because they control the formation of the passivating layer.

The oscillation of the iron electrode forms a diffusive chemical wave around the electrode. If two independent iron oscillators are brought into close proximity, they can communicate with each other through this chemical wave. In this study, the oscillatory pattern of two independently controlled iron electrodes is investigated as a function of the distance between the electrodes.

When current is not observed, the electrode surface is covered by the iron oxide. Because this surface oxide is a thin, n-type semiconductor film, a photoelectrochemical reaction can occur by irradiation with photons at the bandgap energy of the oxide. ${ }^{21}$ This article also shows that the time course of the oscillatory behavior is a function of irradiation intensity and electrode potential. 


\section{Experimental}

The working electrode was an iron wire with purity of $99.5 \%$ purchased from NILACO. The diameter and length of the electrode was 1 and $10 \mathrm{~mm}$, respectively. The electrolyte solution was an aqueous solution containing $1.0 \mathrm{M}$ sulfuric acid. The use of an iron plate electrode with the back surface blocked off was avoided, because surface morphology changed drastically while the reaction proceeded. The reference electrodes used were $\mathrm{Ag} / \mathrm{AgCl}$ and saturated sodium chloride calomel electrode (SSCE), plus a silver quasi-reference electrode. The reference electrode chosen was based on the cell geometry. In the photoirradiation experiments, the reference electrode was optically sealed to avoid any photoinduced shift of the reference electrode potential. The electrode potentials reported are always referenced with respect to SSCE in this article. The counterelectrode was placed in a separated compartment to avoid the effects of the chemical wave.

The electrochemical conditions were controlled by a combination of a potentiostat and a function generator from Hokuto-Denkou, HA-151 and $\mathrm{HB}-111$, respectively. The data were plotted on an X-Y recorder from Yokogawa (Type 3036) or obtained using an analog-to-digital converter from Micro Science (ADS-1598BPC) and stored in an NEC PC-9801RX computer.

For the photoirradiation experiments, a $250 \mathrm{~W}$ Xe lamp was used with a proper combination of optical filters. The irradiation intensity was measured by a power meter from Spectra Physics (Model 407).

\section{Results}

Coupling effects.-A typical current and potential curve for a single iron electrode is shown in Fig. 1. The potential sweep rate was $50 \mathrm{mV} / \mathrm{s}$. On the positive potential sweep, a current maximum and minimum were observed at 0 and $0.2 \mathrm{~V}$, respectively. At $0.3 \mathrm{~V}$, the electrode was fully passivated, i.e., the current was suddenly decreased. On the positive potential sweep, no steady current oscillations were obtained. However, on the negative potential sweep, oscillations were observed between 0.6 and $0.3 \mathrm{~V}$. After that, a current plateau appeared from 0.1 to $-0.3 \mathrm{~V}$. Neither the current maximum nor minimum was observed on the negative potential sweep. When the potential sweep was stopped, a sustained oscillation was obtained around $0.3 \mathrm{~V}$.

Two independent iron oscillators each held at an electrode potential of $0.35 \mathrm{~V}$ were then placed in the solution at a distance of either 25 or $20 \mathrm{~mm}$. Because the oscillating current was large, significant amounts of the iron were dissolved and the diameter of the electrode changed over time. The amplitude of the oscillation is not discussed

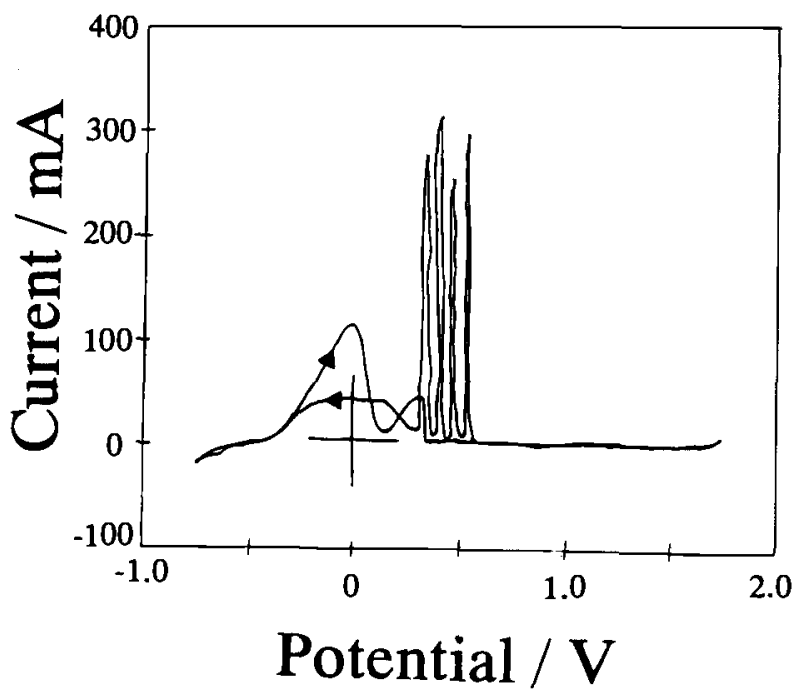

Fig. 1. Typical current and potential relationship of an iron electrode dipped in aqueous $1 \mathrm{M}$ sulfuric acid. here, because it is a complex function of the shape of the electrode. The time courses of the currents were measured and are shown in Fig. $2 a$ and $b$ for the two distances. If the distance was more than $25 \pm 1 \mathrm{~mm}$, there was no correlation between the oscillatory behaviors of the two electrodes, as shown in Fig. 2a. However, if the distance was less than $20 \pm 1 \mathrm{~mm}$, the two waveforms were completely synchronized with each other, as shown in Fig. $2 \mathrm{~b}$. For a distance between 20 and $25 \mathrm{~mm}$, the two electrodes synchronized intermittently. Periods and intervals of synchronization varied randomly as a function of time. Phenomenologically, as the distance between the two electrodes was reduced from 25 to $20 \mathrm{~mm}$, the period of the synchronization was enlarged, and finally the perfect synchronization was obtained. This synchronity was destroyed by inserting a glass slide between the two electrodes. Communication between the two electrodes was blocked by the glass side. These observations show that the carrier of the information for the synchronity is a solution species. These results suggest that coupling strength between the electrodes is a function of both the distance and the geometry of the electrodes.

A very strong coupling was observed at a distance of $3 \mathrm{~mm}$, as shown in Fig. 3. In this experiment, the potentials of the two electrodes were different; the electrode potentials for the upper and the lower oscillatory currents in Fig. 3 were 0.30 and $1.0 \mathrm{~V}$, respectively. Figure 3 shows that the two oscillations are synchronized with antiphase, the current minimum in the upper oscillation corresponding to the current maximum in the lower oscillation. As shown in the figure, the time course of the two waveforms developed into periodic limiting cycles after passing through a transient phase lasting about $60 \mathrm{~s}$.

Photo effects.- The time course of the oscillatory behavior of a single iron electrode was measured under irradiation from a xenon arc lamp. A series of typical results for the photoirradiation experiments are shown in Fig. $4 \mathrm{a}$, b, and $c$ with electrode potentials of $0.315,0.310$, and $0.304 \mathrm{~V}$, respectively. At a potential of $0.315 \mathrm{~V}$, the intervals for the current oscillations were over $60 \mathrm{~s}$ in the dark. This electrode was then irradiated by the Xe lamp as shown in the right side of Fig. 4a. The irradiation induced a stable oscillation with a frequency of about $0.2 \mathrm{~Hz}$. When the electrode potential was $0.31 \mathrm{~V}$, the oscillation frequency under the dark condition was $0.07 \mathrm{~Hz}$, and the frequency became $0.3 \mathrm{~Hz}$ under the irradiation, as shown in Fig. 4b. With an electrode potential of $0.304 \mathrm{~V}$, the frequency under the dark was $0.15 \mathrm{~Hz}$, as shown in Fig. 4c. Under photoirradiation, the oscillating current passed through a transient period with a frequency of $0.7 \mathrm{~Hz}$ and then became a constant current of $70 \mathrm{~mA}$. This series of observations, as shown in Table I, shows that irradiation increases the frequency and that the oscillation is terminated when the electrode potential is too cathodic when the dark frequency is high.
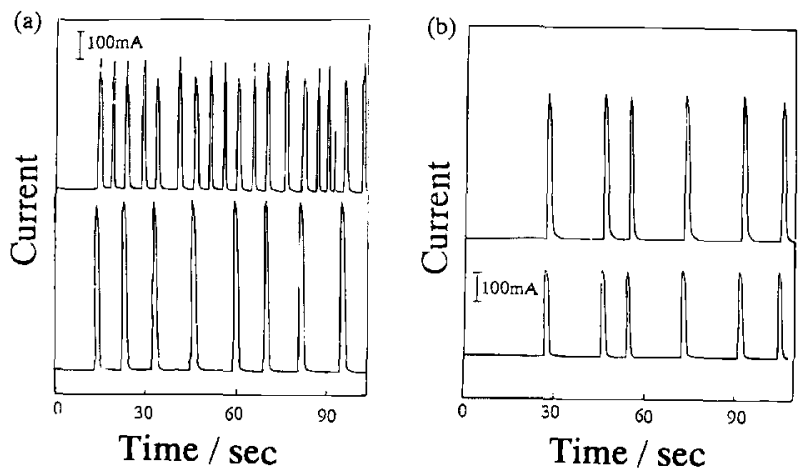

Fig. 2. Time course of two independent iron electrochemical oscillators in aqueous $1 \mathrm{M}$ sulfuric acid at $0.35 \mathrm{~V}$. Distances between the electrodes are 25 and $20 \mathrm{~mm}$ for (a) and (b), respectively. 


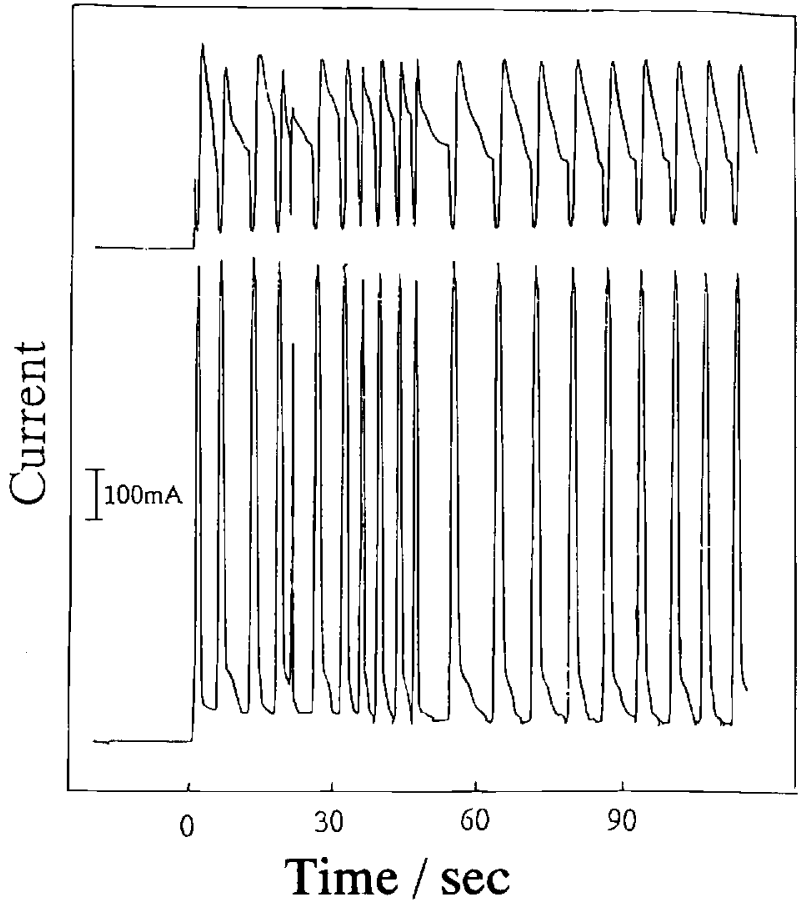

Fig. 3. Time course of two independent iron electrochemical oscillators in aqueous $1 \mathrm{M}$ sulfuric acid. Distance behween the electrodes is $3 \mathrm{~mm}$. Electrode potentials for the upper and lower oscillatory waveforms are 0.3 and $1.0 \mathrm{~V}$, respectively.

In order to investigate the photoirradiation effects systematically, changes in the oscillation frequency were measured as a function of irradiation intensity. The electrode potential was fixed at $0.311 \mathrm{~V}$. Because the oscillatory current was large, the electrode was deformed over time. This change in the shape of the electrode caused a drift in the oscillation frequency. In order to avoid this artifact, the ratio between the oscillation frequencies under the irradiated, $f_{\mathrm{i}}$, and in the dark, $f_{\mathrm{d}}$ i.e., $f_{\mathrm{i}} / f_{\mathrm{d}}$, was plotted as a function of the irradiation intensity, as shown in Fig. 5. A significant frequency change was not observed below an intensity of $25 \pm 3 \mathrm{~mW} / \mathrm{cm}^{2}$, while the frequency ratio increased as intensity increased over $25 \mathrm{~mW} / \mathrm{cm}^{2}$.

\section{Discussion}

The self-sustained current oscillations of the iron electrode have already been macroscopically discussed using the Franck-FitzHugh model. ${ }^{18-20}$ The origin of the nonlinearity of the reaction is passivation by the surface oxide, $\mathrm{Fe}_{2} \mathrm{O}_{3}$. The stable phase on the electrode surface is thermodynamically governed by local $\mathrm{pH}$ and the electrode potential. In the electrolyte solution used, the critical reaction is the electrochemical equilibrium between $\mathrm{Fe}^{2+}$ and $\mathrm{Fe}_{2} \mathrm{O}_{3}$, as shown below

$$
\mathrm{Fe}_{2} \mathrm{O}_{3}+6 \mathrm{H}^{+}+2 e \leftrightarrow 2 \mathrm{Fe}^{2+}+3 \mathrm{H}_{2} \mathrm{O}
$$

The equilibrium potential for this reaction is given by

$$
E_{\text {eq }}=0.5-0.18 \mathrm{pH}-0.06 \log \left(a_{\mathrm{Fe}}^{2+}\right)
$$

This potential equation is referenced with respect to the SSCE and it is called the Flade potential. When the electrode potential is more positive than $E_{\text {eq }}$, the surface is covered by $\mathrm{Fe}_{2} \mathrm{O}_{3}$. If it is more negative than $E_{\text {eq, }}$, the electrodissolution of iron proceeds to form $\mathrm{Fe}^{2+}$. At potentials of around $0.3 \mathrm{~V}$ in $1 \mathrm{M}$ sulfuric acid, the electrodissolution of iron proceeds, which puts $\mathrm{Fe}^{2+}$ ion into solution. In order to maintain electrical neutrality, the concentration of protons decreases in the region close to the electrode surface. This $\mathrm{pH}$ increase in the solution forms more $\mathrm{Fe}_{2} \mathrm{O}_{3}$ on the surface, which inhibits the dissolution reaction and the current decreases. During passivation, the back-diffu- (a)

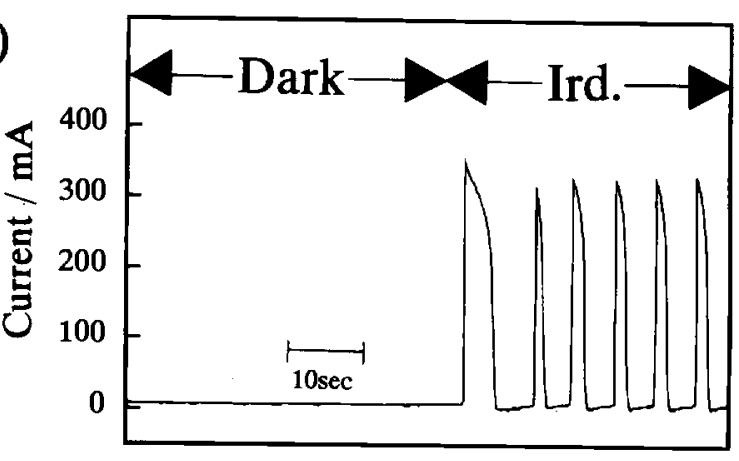

Time

(b)

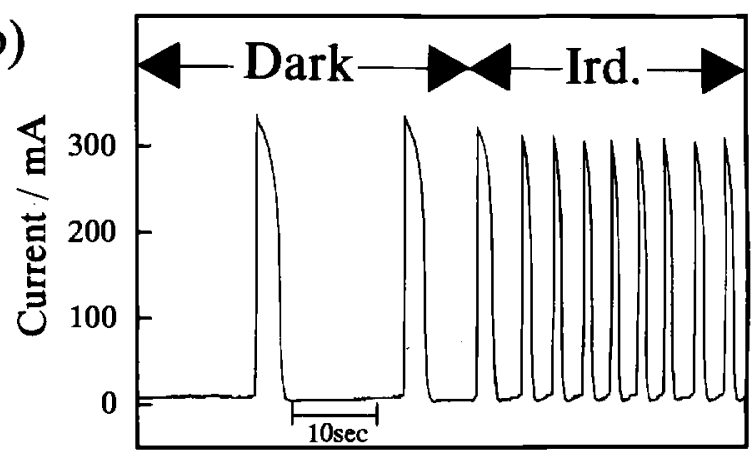

Time

(c)

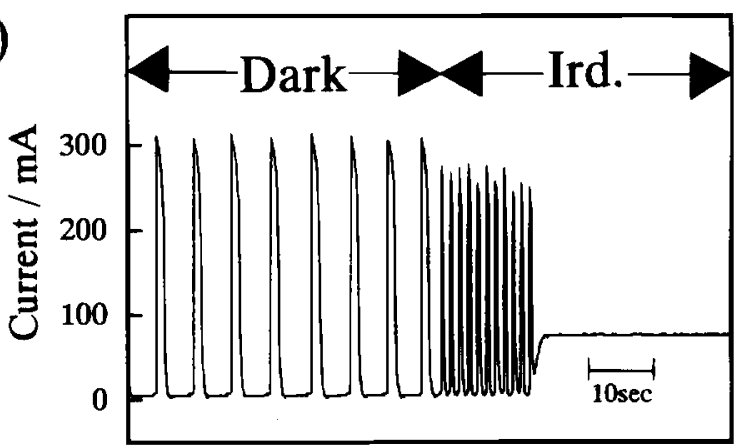

Time

Fig. 4. Irradiation effects for oscillatory waveform of iron electrodes in aqueous $1 \mathrm{M}$ sulfuric acid. Electrode potentials are 0.315 , 0.310 , and $0.304 \mathrm{~V}$ for $(a)$, (b), and (c), respectively.

sion of proton decreases the $\mathrm{pH}$ around the electrode, which induces the electrodissolution again. This is the qualitative scenario explaining the electrochemical oscillation presented by the Franck-FitzHugh scheme in the iron system. ${ }^{18-20}$

Table I. Oscillation frequency change by electrode potential and pholoirradiation.

\begin{tabular}{ccc}
\hline & $\begin{array}{c}\text { Oscillation frequency } \\
\text { under dark } \\
(\mathrm{Hz})\end{array}$ & $\begin{array}{c}\text { Oscillation frequency } \\
\text { under irradiation } \\
(\mathrm{Hz})\end{array}$ \\
\hline 0.315 & $<0.02$ & 0.2 \\
0.310 & 0.07 & 0.3 \\
0.304 & 0.15 & $>0.7^{\mathrm{a}}$
\end{tabular}

a An oscillation was terminated to become a constant current of $70 \mathrm{~mA}$ 


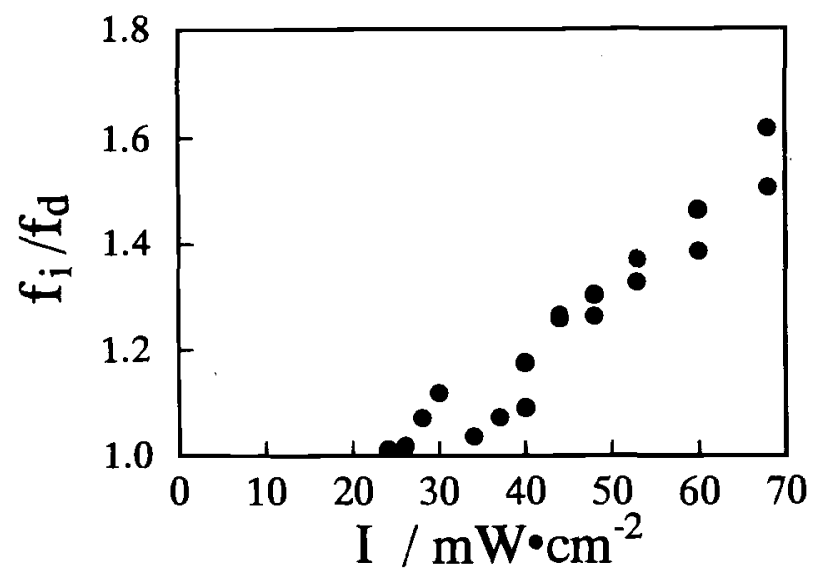

Fig. 5. Frequency ratio between under dark and under irradiation as a function of irradiation intensity. Electrode potential is $0.311 \mathrm{~V}$.

In order to obtain the oscillatory behavior, the FranckFitzHugh scheme implicitly requires that the electrochemical reaction on the iron electrode discontinuously changes at the Flade potential. However, as shown in Fig. 1, the current passivation is not as sharp as a step function as expected from the Franck-FitzHugh scheme. The active area of the electrode gradually decreases as the electrode potential goes from the active to the passive region. Instead of assuming the discontinuous behavior, Koper and Sluyters have modified the classical model of FranckFitzHugh considering the role of the uncompensated ohmic resistance. ${ }^{22}$ The uncompensated potential drop by the ohmic resistance between the iron and reference electrodes shifts the actual electrode potential to the cathodic direction. As the current decreases at the electrode more positive than the Flade potential, the uncompensated ohmic drop increases the average current density on the active portion of the electrode. This increases the local $\mathrm{pH}$ near the active area and induces passivation without the supposedly discontinuous reaction change at the Flade potential based on the Franck-FitzHugh model.

When two iron electrodes are closely located, each electrode emits both proton and ferrous ion waves. When electrodissolution starts at one electrode, the proton wave decreases the $\mathrm{pH}$ on the surface of the other electrode. This increases the $E_{\text {eq }}$ value for the other electrode. Then the surface oxide of the second electrode is removed and it creates a current pulse. The proton wave induces the inphase synchronity between the two electrodes, as shown in Fig. $2 \mathrm{~b}$. When the distance between the electrodes is large, $\mathrm{pH}$ modulation at the second electrode is not enough to activate the passivated surface, and the synchronity is not observed, as shown in Fig. 2a.

If the ferrous ion is the carrier of the information for the synchronity, the two electrodes would synchronize in antiphase, because increase of the local concentration of ferrous ion decreases $E_{\mathrm{eq}}$ for the other electrode. Although the $\mathrm{pH}$ in the solution might be well buffered by $1 M$ sulfuric acid, as the mobility of the proton is much higher than $\mathrm{Fe}^{2+}$ and $E_{\text {eq }}$ is more than three times more sensitive to $\mathrm{pH}$ than to concentration of $\mathrm{Fe}^{2+}$, the proton wave propagated by the space charge of ferrous ion can modulate the local $\mathrm{pH}$ of the other electrode.

In the case of a closer proximity of the electrodes with different potentials, shown in Fig. 3 , the pattern of the synchronization was different from the case of Fig. $2 b$. Because the electrode potential for the bottom oscillatory pattern in Fig. 3 is $1 \mathrm{~V}$, which is more positive than the redox potential of $E_{\mathrm{Fe}^{3+}+\mathrm{Fe}^{2+}}, 0.54 \mathrm{~V},{ }^{23}$ the electrode emits $\mathrm{Fe}^{3+}$ during the electrodissolution process. The oscillatory flux of $\mathrm{Fe}^{3+}$ is reduced on the other electrode, which reduces the current. The antiphase synchronity shown in Fig. 3 is caused by chemical communication through the $\mathrm{Fe}^{3+}$ wave.
The passive oxide film formed during the anodic dissolution of iron is known to behave as an n-type semiconductor. The photoelectrochemical response of $\mathrm{Fe}_{2} \mathrm{O}_{3}$ is well studied in relation to photoelectrochemical solar energy conversion. ${ }^{21,24,25}$ Electron and hole pairs are created in the $\mathrm{Fe}_{2} \mathrm{O}_{3}$ by photoabsorption. The photocreated holes are accumulated on the surface and some of them destroy the $\mathrm{Fe}_{2} \mathrm{O}_{3}$ lattice, because the decomposition potential of the material is located in the bandgap region under acidic conditions. ${ }^{25}$ The photoresponse of thick polycrystalline $\mathrm{Fe}_{2} \mathrm{O}_{3}$ film has been observed in the spectral region from 800 to $400 \mathrm{~nm} .{ }^{24}$ Thus, the frequency increase under photoirradiation shown in Fig. 4 and 5 is caused by the photocorrosion of the surface oxide, ${ }^{26}$ which activates the electrodes. Under irradiation, the surface oxide is removed at a more rapid rate by the photocorrosion. Thus, irradiation reduces the period of the passivation stage and increases oscillatory frequency.

Another possible mechanism for the frequency change by irradiation could be the temperature increase by local heating. Podesta et al. investigated frequency change as a function of temperature. ${ }^{27}$ They found a linear relationship between the logarithm of the frequency and the inverse of the temperature. The apparent activation energy for the $\log F-(1 / T)$ plot was $3.6 \mathrm{kcal} / \mathrm{mol}$ for oscillation of the iron electrode. The temperature rise caused by irradiation of $70 \mathrm{~mW} / \mathrm{cm}^{2}$ was $3^{\circ} \mathrm{C}$ in our experiment. Because the frequency ratio increase by this thermal heating would be expected to be less than 1.06 , the magnitude of the results in Fig. 4 and 5 do not seem to be explained by only the thermal heating effect.

\section{Conclusion}

Although the experiment is relatively simple, this paper demonstrates that coupling can occur between closely spaced iron electrodes and that external perturbation can effect such iron electrochemical oscillators. Detailed mathematical analysis is underway in our laboratory.

\section{Acknowledgment}

This work was partially supported by a Grant-in-Aid on Priority Area Research on "Free Radical Science" from the Ministry of Education, Science and Culture, Japan.

Manuscript submitted June 26, 1995; revised manuscript received April 8, 1996 .

Hokkaido University assisted in meeting the publication costs of this article.

\section{REFERENCES}

1. S. K. Scott, Chemical Chaos, Clarendon Press, Oxford (1991).

2. M. Eiswirth, A. Freund, and J. Ross, in Advances in Chemical Physics, Vol. LXXX, I. Prigogine and S. A. Rice, Editors, p. 127, John Wiley \& Sons, New York (1991).

3. M. Dolnik, L. Abbott, and I. R. Epstein, J. Phys. Chem., 98, 10124 (1994).

4. F. Argoul, A. Arneodo, P. Richetti, J. C. Roux, and H. L. Swinney, Acc. Chem. Res., 20, 436 (1987).

5. J. C. Roux, R. H. Simoyi, and H. L. Swinney, Physica, 8D, $257(1983)$

6. D. Aronson, R. McGehee, I. Kevrekidis, and R. Aris, Phys. Rev. A., 33, 2190 (1986).

7. M. Dolnik, J. Finkeova, I. Schreiber, and M. Marek, $J$. Phys. Chem., 93, 2764 (1989)

8. J. Boissonade and P. DeKepper, ibid, 84, 501 (1980).

9. M. F. Crowley and I. R. Epstein, ibid., 93, 2496 (1989).

10. C. G. Hocker and I. R. Epstein, J. Chem. Phys., 90, 3071 (1989).

11. R. Imbihl, M. P. Cox, and G. Ertl, ibid., 84, 3519 (1986).

12. M. P. Cox, G. Ertl, and R. Imbihl, Phys. Rev. Lett., 54, 1725 (1985).

13. R. Imbihl, Th. Fink, and K. Krischer, J. Chem. Phys., 96, 6236 (1992).

14. S. Nakabayashi and A. Kira, J. Phys. Chem., 96, 1021 (1992).

15. S. Nakabayashi and K. Uosaki, Chem. Phys. Lett., 217, 163 (1994). 
16. F. Raspel and M. Eiswirth, J. Phys. Chem., 98, 7613 (1994).

17. Y. Xu and M. Schell, ibid., 94, 7137 (1990).

18. G. L. Griffin, This Journal, 131, 18 (1984).

19. A. J. Pearlstein and J. A. Johnson, ibid., 136, 1290 (1989).

20. Y. Wang, J. L. Hudson, and N. I. Jaegar, ibid., 137, 485 $(1990)$.

21. K. L. Hardee and A. J. Bard, ibid., 123, 1024 (1976).

22. M. T. M. Koper and J. H. Sluyters, J. Electroanal.
Chem., 347, 31 (1993)

23. A. J. Bard and L. R. Faulkner, Electrochemical Methods, John Wiley \& Sons, New York (1980).

24. L.-S. R. Yeh and N. Hackerman, This Journal, 124, 833 (1977)

25. J. H. Kennedy and M. Anderman, ibid., 130, 848 (1983).

26. T. D. Burleigh, Corros. Sci., 31, 745 (1990).

27. J. J. Podesta, R. C. V. Piatti, and A. J. Arvia, This Journal, 126, 1363 (1979).

\title{
Plating and Stripping of Sodium from a Room Temperature 1,2-Dimethyl-3-propylimidazolium Chloride Melt
}

\author{
Gary E. Gray, Jack Winnick, ${ }^{* *}$ and Paul A. Koh"** \\ School of Chemical Engineering, Georgia Institute of Technology, Atlanta, Georgia 30332-0100, USA
}

\section{ABSTRACT}

Room temperature molten salts consisting of 1,2-dimethyl-3-propylimidazolium chloride and aluminum chloride have been examined as possible electrolytes for a room temperature design of the sodium/iron(II) chloride battery. This work examines the conditions which provide the most efficient reduction and oxidation of sodium from a sodium chloride buffered, neutral melt. Most work was performed on a tungsten substrate using cyclic voltammetry. Melts were treated with gaseous $\mathrm{HCl}$ using a closed electrochemical cell which allowed for quantification of the effect of $\mathrm{HCl}$ on the electrochemical behavior of sodium in the molten salt. The $\mathrm{HCl}$ threshold partial pressure was less than $1 \mathrm{kPa}$ for sodium plating. This result was complicated by the slow equilibrium between gaseous $\mathrm{HCl}$ and that dissolved in the molten salt; the effect of $\mathrm{HCl}$ addition was found to last for months, demonstrating the slow equilibrium. Small amounts of water contamination were found to produce a similar effect. At elevated temperatures the melt had higher conductivity, an order of magnitude higher current densities, and higher coulombic efficiency.

\section{Introduction}

The need for near-ambient temperature batteries has stimulated research into a variety of battery technologies. Numerous efforts have focused on the nickel/metal hydride and lithium-ion batteries. The goals of these activities have been to develop secondary batteries with high energy density, recyclability, and low cost. Despite these efforts, there remains a need for a low-cost secondary battery using mundane materials, with minimal safety and environmental issues, which can achieve high energy density.

The "Zebra Cell" is a medium-temperature battery ${ }^{1}$ utilizing a sodium anode and an $\mathrm{FeCl}_{2}$ cathode (later changed to $\mathrm{NiCl}_{2}$ ) in a molten electrolyte composed of $\mathrm{NaCl}$ and $\mathrm{AlCl}_{3}$. The operational temperature of the battery is above $220^{\circ} \mathrm{C}$ because of the solid-liquid phase equilibrium of the electrolyte. At this temperature the Zebra Cell has an energy density of about $100 \mathrm{Wh} / \mathrm{kg}$ and a power density of about $110 \mathrm{~W} / \mathrm{kg}$. These characteristics, combined with the mundane nature of the cell components, have stimulated interest in its use, for example, in electric cars.

One of the less desirable aspects of the Zebra Cell is the need for a solid-state separator between the $\mathrm{Na}$ (liquid) anode and the electrolyte; direct contact results in a chemical reaction producing $\mathrm{Al}$

$$
3 \mathrm{Na}+\mathrm{NaAlCl}_{4} \rightarrow \mathrm{Al}+4 \mathrm{NaCl}
$$

The $\beta^{\prime \prime}$-alumina separator used in the Zebra Cell is a $\mathrm{Na}^{+}$ conductor with a conductivity of $0.083 \mathrm{~S} / \mathrm{cm}$ at $220^{\circ} \mathrm{C}$. An appreciable voltage drop (ca. $350 \mathrm{mV}$ ) results from use of the separator under typical operating conditions. ${ }^{2}$ Further, the $\beta^{\prime \prime}$-alumina must be cast into tubes, adding cost and potential reliability concerns.

Recently, a room temperature analogue of the Zebra Cell has attracted interest. A nonaqueous, molten salt with properties ${ }^{3}$ similar to $\mathrm{NaAlCl}_{4}$ may offer characteristics that could lead to a sodium (anode)/metal chloride (cathode) battery where the sodium anode is maintained in the

* Electrochemical Society Student Member.

* Electrochemical Society Active Member. solid state so that no separator is needed. In addition to providing reasonable conductivity at low temperature, this melt must also: $(i)$ permit efficient plating/stripping of $\mathrm{Na}$, (ii) provide a stable environment for the sodium anode without side reactions, such as producing aluminum (Eq. 1) or other parasitic reactions, and (iii) permit a reversible cathodic reaction at least $2 \mathrm{~V}$ positive of the $\mathrm{Na}$ electrode

Room temperature molten salts are based on $\mathrm{AlCl}_{3}$, analogous to the high-temperature melts, except that an aromatic organic chloride replaces most of the $\mathrm{NaCl}$, lowering the melting points well below room temperature, to as low as $-50^{\circ} \mathrm{C} .{ }^{4} \mathrm{Na}^{+}$conduction is achieved by adding some $\mathrm{NaCl}$ to the melts; however, the melts have only limited capacity to dissolve $\mathrm{NaCl}$. Several types of organic chlorides have been examined, including several imidazolium chlorides.

The most studied organic chloride has been 1-methyl-3ethyl imidazolium chloride (MEIC), due to its relatively high conductivity in the $\mathrm{AlCl}_{3}$ melt, $0.035 \mathrm{~S} / \mathrm{cm}$ at room temperature. Its electrochemical window is most attractive, ca. $4.7 \mathrm{~V}$, between chlorine evolution at the positive potential limit and the apparent reductive dimerization of the imidazolium at the negative potential limit. Reduction of the imidazolium cation to the neutral radical lies very near that of the $\mathrm{Na} / \mathrm{Na}^{+}$couple. Still, sodium was able to be plated from the room temperature melt using a mercury electrode. ${ }^{5}$ The addition of either hydrogen chloride (in various forms) or thionyl chloride has been found to enable the plating and stripping of sodium from the MEIC/NaAlCl ${ }_{4}$ melt at solid electrodes. The role of these additives is not well understood. Additionally, most of these additives appear to provide short-lived effects ranging from hours to days. ${ }^{6-9}$

A critical parameter for battery applications using the sodium couple in these room temperature melts is the coulombic efficiency. The coulombic efficiency is the ratio of the number of coulombs passed during oxidation of sodium (during the discharge cycle) to the number passed during reduction (charging cycle). It would be most desir- 